\title{
An Investigation into the Adhesion Strength of Diamond Like Carbon Multilayer Coating (DLC/TiN/Ti/Cu/Ni)
}

\author{
B. RAMAMOORTHY, BINU C. YELDOSE \\ Manufacturing Engineering Section, Department of Mechanical Engineering, \\ Indian Institute of Technology Madras, Chennai, India \\ Email:ramoo@iitm.ac.in
}

\begin{abstract}
Advancement in vacuum technologies and vapor deposition processes during last decades has led to the introduction of many modern coatings on metal cutting tools. Even in such an advanced vacuum coating techniques, the failure is not due to the wear of the coating but rather due to the lack of coating adhesion to the substrate. In this work, the coating adhesion test results were performed which is based on the Rockwell indentation tests. This coating adhesion tests were performed as per VDI standards 3198, 1991 for d.c. magnetron sputter deposition of diamond like carbon multilayer coating (DLC / TiN/ Ti / Cu / Ni) on tool substrate. Multilayer coating was deposited on tool substrates at different sputtering parameters/conditions such as power density, partial pressure, substrate temperature and reactive gases. The coated multilayer films were characterized by experimental techniques such as X-ray diffractometer which measures the material deposited, micro Raman spectroscopy and TEM to check DLC, Rockwell indentation to examine adhesion strength, optical profilometer to measure thickness of coating. Ni increases the $\mathrm{Cu}$ adhesion on tool substrate. $\mathrm{Cu}$ accommodates the shear stress induced by the films / substrate and the mismatch in thermal expansion coefficient, while Ti and TiN promote better DLC bonding. As the target power was increased the adhesion strength, micro hardness and deposition rate were observed to improve. Increase in target power and substrate temperature enhances adhesion strength. Proper substrate preparation and sequence of cleaning processes are the crucial factors for the enhancement of adhesion strength. The sputter deposition conditions for the above mentioned multilayer coatings are identified in this work to get improved quality with particular reference to adhesion and surface finish.
\end{abstract}

Keywords: cleanliness, sputtering, multilayer, adhesion, micro hardness

\section{Introduction to Surface Engineering}

In the recent past, the coating technology has advanced tremendously and it is performed with enormous skill and efficiency to produce quality components for many engineering applications. With advances in the last two decades, chemical vapour deposition (CVD), physical vapour deposition (PVD) processes are widely used to deposit hard, super hard, soft and combining hard/soft coating applications such as dies, jigs, cutting tools and bio compatible materials used in medical applications.

Hard wear resistant coatings are generally used in tooling applications where it enhances tool lifetime of two to ten times [1]. Since last two decades coating technologies like CVD, PVD and other coating processes have been developed for depositing various types of hard coatings on dies, jigs, cutting tools and machine components in order to improve their resistance to seizure and wear. The durability and quality of any such coating depends not only on the hardness, toughness, seizure and wear resistance of the coatings but also strongly on the adhesion to the substrate. Hence it is vital to consider the quality of adhesion strength of the coating. The adhesion strength of a coating is the amount of energy required to delaminate the coating from the substrate, but that energy is not easily measurable. Therefore, the force required to delaminate the coatings from the substrate is considered as a standard indication of the adhesion strength. The mismatch in thermal expansion coefficient of multilayer coating material and substrate is responsible for the above cited shortcomings [2]. Even when using well developed vacuum coating technology in hard coatings on tool steel, the failure mode is not due to wear of coating but due to adhesive failure [3].

The structure and properties of multilayer deposition of $\mathrm{Cr}-\mathrm{B}$ and $\mathrm{Cr}-\mathrm{B}-\mathrm{N}$ films by magnetron sputtering process showed that, under optimal parameters, hardness and properties were enhanced [4]. The indentation techniques and its applications to thin film characterization are very important for determining the mechanical per- 
formance of coated substrate [5].

The multilayer coating of $\mathrm{Cr} / \mathrm{Cr}_{2} \mathrm{O}_{3}$ were deposited using reactive magnetron sputtering with a total thickness of $7 \mu \mathrm{m}$ on a tool steel substrate showed that grain size increased with the increase in coating thickness [6]. The multilayer TiCrBN/WSe ${ }_{x}$ coatings were deposited using sputtering process; ion implantation was employed at the initial stage of deposition for 5 minutes to enhance film adhesion. The coatings were characterized in terms of their adhesion strength, micro hardness and friction. The wear test verifies the decrease in the friction coefficient [7]. A multilayer gradient $\mathrm{Ti}(\mathrm{C}, \mathrm{N})$ coating were synthesized using magnetron sputtering process, better wear resistance is observed in continuous turning rather than in interrupted cutting [8].

A multilayer coating of TiN/TiBN with different bilayer thicknesses were carried out on a AISI M42 tool steels at room temperature using magnetron sputtering in an $\mathrm{Ar}-\mathrm{N}_{2}$ gas mixture, the highest adhesion strength was observed at an optimum combination and thickness of multilayer deposition [9].

Comprehensive studies on seven different metallic interlayers (W, Mo, Nb, Cr, Ti, Ag and Al) using sputtering process reported that the interlayer in TiN on HSS showed better adhesion properties [10]. A thin diamond like carbon films were deposited onto a steel substrate using plasma immersion ion implantation process and a nitrogen interlayer was deposited on the substrate surfaces before depositing the DLC films which enhanced the adhesion strength and wear resistance [11].

Thus, in order to design tailored coating / substrate systems successfully, the most important aspect to be considered is the mechanism of adhesion.

Adhesion and micro hardness are considered to have crucial role on coating processes [12] and DLC coating has in general good adhesion and hardness properties. The direct coating of DLC on many substrate materials may not render the requisite adhesion due to mismatch in properties such as thermal expansion coefficient etc. The coated layers are chosen in such a way to take care of the thermal expansion mismatch and shear stress induced to get better adhesion. Since the top layer is DLC, normally the hardness of the coating is achieved will be very high which is likely to be a major advantage for many engineering applications. However, till now, little investigation has been reported about the properties of DLC/ $\mathrm{TiN} / \mathrm{Ti} / \mathrm{Cu} / \mathrm{Ni}$ multilayer coating on tool substrates with DLC coating as the top layer. In this present work, adhesion test results are based on the Rockwell indentation tests as per VDI standard 3198, 1991 for a d.c. magnetron sputtering process. A graded interlayer approach is tried out to enhance the coating adhesion. The coated films were characterized and results are reported and analyzed.

\section{Basic Aspects of Adhesion}

\subsection{The Adhesion Mechanisms}

The mechanisms of adhesion can be mainly divided into two groups: 1) mechanical interlocking 2) chemical bonding.

In all substrate/coating systems, these adhesion mechanisms individually or together are responsible for adhesion. Very often, one of the mechanisms plays a dominant role. These mechanisms can be subdivided further and are shown Figure 1. Mechanical interlocking can be divided into locking by friction and locking by dovetailing. Chemical bonding is divided into ionic, covalent and metallic bonding. The forces that can be transmitted by mechanical interlocking depend on the size and geometry of the locking sites. These sites can vary from mechanically machined dovetails, grooves and other macroscopic shapes to undercut porosity by pickling and micro roughness produced by grit blasting. Depending on the topographical results, three different effects are possible. The first is the increase in surface area by which any type of physical or chemical bonding is more effective. The second possibility consists of sites which give rise to friction between coating and substrate material. This is particularly evident where the frictional force $F_{f}=\mu F_{N}$ is high owing to a high coefficient of friction $\mu$ and high normal stresses $F_{N}$. These stresses can be raised by the coating shrinking on the substrate because of the high coating temperature and high coefficient of expansion of the coating material. The third effect is the form of locking in which the forces transmitted depends on the mechanical properties of the materials involved. The magnitude of locking effect is highly influenced by the wetting properties of the coating. It is very sensitive to the
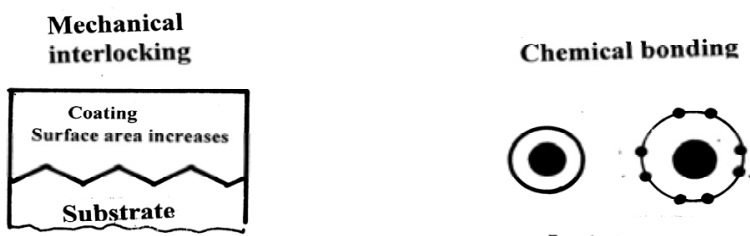

Ionic bonds
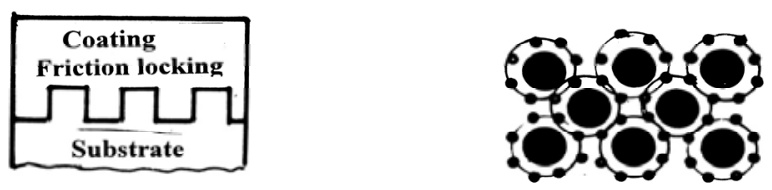

Covalent bond
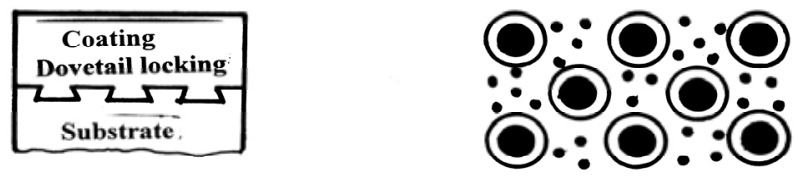

Metallic bond

Figure 1. Schematic illustration of the different mechanical and chemical bonding mechanisms [3] 
type of coating technology, the materials used and mostly to the coating parameters. Physical bonds are very weak. Their interaction energies are less than $50 \mathrm{~kJ} \mathrm{~mol}^{-1}$ over a distance of 0.3 to $0.5 \mathrm{~nm}$. Chemical bonds are comparatively strong with energy levels between 110 and $260 \mathrm{~kJ} \mathrm{~mol}^{-1}$ and in the case of metallic bonds up to 1000 $\mathrm{kJ} \mathrm{mol}^{-1}$ with atomic and ionic bonds of 0.1 to $0.2 \mathrm{~nm}$.

The forces of adhesion resulting from these energies vary by at least one order of magnitude for physical and chemical bonding, e.g. $500 \mathrm{~N} \mathrm{~mm}^{-2}$ for hydrogen bonding and $5000 \mathrm{~N} \mathrm{~mm}^{-2}$ for chemical bonding [13-16].

\subsection{Importance of Graded Multilayer Coating}

Multilayered materials with individual layers of less than a micrometer in thickness are widely used in thin film coatings, which can exhibit substantial enhancement in hardness or strength. The enhancements in hardness can be as much as $100 \%$ when compared to the value expected from the rule of mixtures, which would have been a weighted average of the hardness for the constituents of the two layers.

There are many factors/theories that contribute/explain enhancement of hardness and strength in multilayer. These can be summarized as,

1) Hall-Petch behavior

2) Qrowan strengthening

3) Image effects

4) Coherency and thermal stresses

5) Composition modulation

Hall-Petch behavior is related to dislocations pile-up at grain boundaries. This pile-up at grain boundaries impedes the motion of dislocations. For materials with a fine grain structure there are many grain boundaries which block the movement of dislocations across the grain boundaries. In polycrystalline multilayer, the grain size decreases with the decrease in layer thickness. The effect of an increased strengthening with decrease in grain size $d_{g}$ is described by the well known Hall-Petch relation (HPR).

$$
Y=Y_{0}+k_{H P} \cdot d_{g}^{-0.5}
$$

where $\mathrm{Y}$ is the enhanced yield stress, $\mathrm{Y}_{0}$ is the yield stress for a single crystal, and $k_{H P}$ is a constant and grain size reduction has a negative effect on creep strength, especially for metallic materials.

There is still an ongoing argument on the Hall-Petch behaviour in nano structured multilayer. The basic model assumes many dislocations pile-up, but such large dislocations pile-up is not seen in small grains and is unlikely to be present in multilayer. As a direct consequence, studies have found a range of values, between 0 and -1 , for the exponent in (Equation 1), rather than the - 0.5 predicted for Hall-Petch behavior.

Orowan strengthening is due to dislocations in layered materials being effectively pinned at the interfaces. As a result, the dislocations are forced to bow out along the layers. In narrow films, dislocations are pinned at both the top and bottom interfaces of a layer and bow out parallel to the plane of the interface. Forcing a dislocation to bow out in a layered material requires an increase in the applied shear stress beyond a limit that is required to bow out a dislocation in a homogeneous sample. This additional shear stress would be expected to increase as the film thickness is reduced.

Image effects were suggested by Koehler [17] as a possible source of enhanced yield stress in multilayered materials. If two metals, $\mathrm{A}$ and $\mathrm{B}$, were used to make a laminate and one of them, $\mathrm{A}$, has a high dislocation line energy, but the other, $\mathrm{B}$, has a low dislocation line energy, then there will be an increased resistance to dislocation motion due to image forces. However, if the individual layers are thick enough that there may be a dislocation source present within the layer, then dislocations could pile-up at the interface. This will create a local stress concentration point thereby resulting in an enhancement in strength. If the layers are thin enough, there will be no dislocation source present; the enhanced mechanical strength may be substantial. The consequence of image effects in reducing the thickness of the individual layers in a multilayer is that it prevents dislocation sources from being active within the layer.

For many multilayer systems there is an increase in strength as the thickness of coating is reduced, but there is a critical thickness (e.g. $3 \mathrm{~nm}$ for the $\mathrm{W} / \mathrm{NbN}$ multilayer) below which the strength falls. One explanation for the fall in strength involves the effects of coherency and thermal stresses on dislocation energy. While the energy of dislocations is maximum or minimum in the centre of layers for image effects, the energy maxima and minima are at the interfaces for coherency stresses. Combining the effects of varying moduli and coherency stresses show that the dependence of strength on layer thickness has a peak near the repeat period where a coherency strain begins to decrease.

Another source of deviations in behavior is the imperfect nature of interfaces. With the exception of atomically perfect epitaxial films, interfaces are generally not atomically flat and there is some inter diffusion [18-21].

\section{Experimental Procedure}

\subsection{Substrate Surface Preparation}

For this study WC (a typical commercially available WC turning indexable inserts) was used as substrate. The substrate surface preparation involves prolonged step by step sequential careful operations. Substrate surface preparation processes involve two phases, grinding phase and polishing phase.

The purpose of the grinding phase is to remove damage from cutting, planerize the substrate and to remove 
material approaching the area of interest. It involves, sequentially hand grinding of substrates with $\mathrm{SiC}$ abrasive paper of mesh sizes $120,220,320,400,600,800$, 1000 and 1200 . The polishing phase involves the use of alumina abrasives powder of 600 mesh sizes with water slurry, used as a primary polishing abrasive and subsequently using a diamond paste of 14,000 mesh size with a specially prepared lubricant as a final step of polishing for obtaining a mirror finished substrates $(\mathrm{Ra} \sim 0.014 \mu \mathrm{m})$. Extreme care has taken such that, never drying out of lubricant takes place while polishing the substrate with diamond paste, because it will damage the surface of the polishing cloth with the polishing motions and create scratch on the substrate surface. These operations in the polishing phase were carried out using polishing machines.

A mirror finished substrate surface is mandatory for thin film coating. If not, the impingement of species will incident on the substrate surface at an oblique angle, instead of falling normally on the substrate. This occurs due to the shadowing effect of the neighboring columns oriented towards the incident species. This shadowing effect promotes enhancement of surface roughness. A smoother coating will improve wear resistance whereas high micro projections in a rough coating can be easily knocked off during sliding, resulting in a catastrophic failure of the coating [22,23].

\subsection{Substrate Cleaning Process}

Adhesion quality depends on the process of surface preparation and surface cleanliness. Substrate cleaning process consists of four steps; 1) ultrasonically degassing 2) ultrasonically degreasing 3) deionized water rinsing 4) ultrahigh vacuum heating.

The surface of the substrate being cleaned has been considered as flat but in reality surfaces are seldom flat, instead being comprised of hills, valleys and convolutions of all description. The mechanism of ultrasonic cleaning is by cavitations and the solvent liquid selection was made on the basis of higher surface tension and lower vapor pressure.

Degassing is the process of removing small suspended gas bubbles and dissolved gases from a solvent liquid prior to using it as a vehicle for ultrasonic degreasing. Dissolved gases, if not removed migrate into cavitations bubbles during their formation and prevents them from imploding violently, thus reducing the cleaning effect and also these gas bubbles absorb ultrasonic energy reducing the sound intensity. These dissolved gases act as a cushion to the imploding cavitations bubble, which is much like an air bag in a car. Trichloroethylene, acetone and isopropyl alcohol were degassed by operating with ultrasonic vibrations for a period of 15 minutes. If small bubbles were not seen rising to the liquid surface during ultrasonic degreasing operation, then it indicates that the solvent was completely degassed.

The degreasing process involves, ultrasonic agitation cleaning of substrate in trichloroethylene, acetone and isopropyl alcohol for about 15 minutes each and rinsing in deionized water. After each process, substrates were dried with hot air. Rinsing in deionized water removes residues of the cleaning chemistry and the contaminants which were loosened to leave the substrate surface and made the substrate completely free of residue.

This mirror finished substrates have nascent surface, which is chemically very active and extremely easy to scratch, hence special care was taken to keep the substrates absolutely clean during cleaning process [24-33].

Finally, for ultra-high vacuum cleaning, the vacuum chamber was evacuated to a pressure less than $5 \times 10^{-6}$ mbar and the substrates were heated for about 45 minutes at a substrate surface temperature of $400^{\circ} \mathrm{C}$. Proper metal tooling and hand gloves were used for handling of the substrates during and after cleaning to avoid the transfer of human body oil to substrate.

\subsection{Applied Coating Technology}

Five layers of different materials were deposited: DLC/ $\mathrm{TiN} / \mathrm{Ti} / \mathrm{Cu} / \mathrm{Ni}$. Each layer was coated for 30 minutes duration to produce same layer thicknesses within an approximate range of $0.4-0.5 \mu \mathrm{m}$. The target to substrate distance was kept at $5 \mathrm{~cm}$. The substrate material used in the experiments was cemented carbide turning inserts of geometry with $6 \%$ cobalt and they were arranged on a substrate holder, which was integrated with a heater. Schematic illustration of the sputtering apparatus used is shown in Figure 2.

The deposition processes were carried out in two target planar magnetron sputtering system, where two different layers of material can be coated under the same vacuum conditions. This system contains two cathodes, placed on upper portion of the chamber, with the corresponding magnets behind the cathodes in a water-cooled bell jar vacuum enclosure. Magnets were arranged to produce closed magnetic fields for confining the plasma around the target area, thus giving intense ion bombardment to the growing film on the surface of the substrate. This equipment consists of a rotary pump and a diffusion pump, capable to create vacuum up to $1 \times 10^{-6} \mathrm{mbar}$.

Pure nickel, copper, titanium and graphite discs of 2-inch diameter and $3 \mathrm{~mm}$ thickness were used as target material for the deposition of DLC/TiN/Ti/Cu/Ni coating respectively. The TiN was deposited using sputtering of pure titanium with argon gas and nitrogen as reactive gases. Initially the $\mathrm{Ni}$ and $\mathrm{Cu}$ targets were fixed on the target holder. The substrate was kept below the Ni target position and Ni layer deposition was carried out for 30 minutes duration. Then the substrate was moved to $\mathrm{Cu}$ target position and second layer namely $\mathrm{Cu}$ deposition 


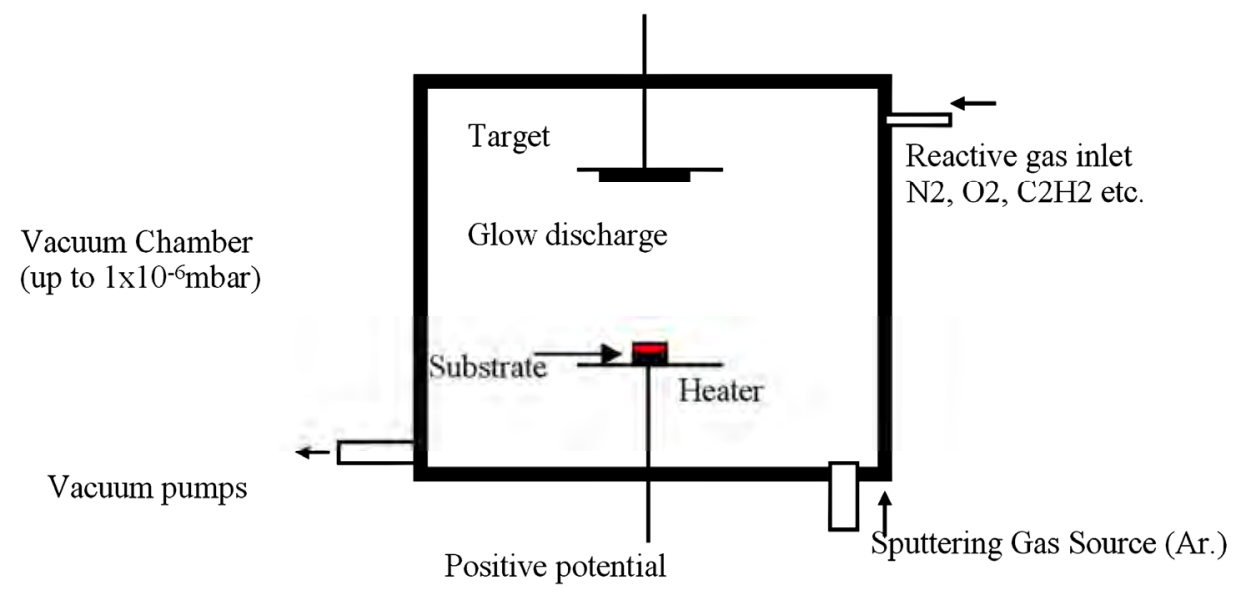

Figure 2. Schematic illustration of the sputtering apparatus used

Table 1. Deposition conditions used in experiments for multilayer coating ( $\mathrm{Ni}$ - first layer, $\mathrm{Cu}$ - second layer, $\mathrm{Ti}$ - third layer, TiN- fourth layer and the DLC - fifth layer) each layer 30 minutes deposition duration on WC substrates

\begin{tabular}{ccccccc}
\hline $\begin{array}{r}\text { Sl. } \\
\text { No. }\end{array}$ & Target material & $\begin{array}{c}\text { Sputtering/ } \\
\text { Reactive gas }\end{array}$ & $\begin{array}{c}\text { Material } \\
\text { deposited }\end{array}$ & $\begin{array}{c}\text { Chamber } \\
\text { Pressure } \\
\text { (mbar) }\end{array}$ & $\begin{array}{c}\text { Power } \\
(\mathbf{W})\end{array}$ & Substrate temperature $\left({ }^{\mathbf{o}} \mathbf{C}\right)$ \\
\hline 1 & $\mathrm{Ni}$ & $\mathrm{Ar}$ & $\mathrm{Ni}$ & $4 \times 10^{-3}$ & & $100-400$ \\
2 & $\mathrm{Cu}$ & $\mathrm{Ar}$ & $\mathrm{Cu}$ & $4 \times 10^{-3}$ & & \\
3 & $\mathrm{Ti}$ & $\mathrm{Ar}$ & $\mathrm{Ti}$ & $4 \times 10^{-3}$ & $100-300$ & No substrate heating during \\
4 & $\mathrm{Ti}$ & $\mathrm{Ar} / \mathrm{N}_{2}$ & $\mathrm{TiN}$ & $5 \times 10^{-3}$ & & $\begin{array}{l}\text { DLC deposition } \\
5\end{array}$ \\
\hline
\end{tabular}

was performed for 30 minutes. Then both the targets were removed. Thereafter $\mathrm{Ti}$ and graphite targets were placed on the target holder. The third layer deposited was $\mathrm{Ti}$; and then the fourth layer TiN deposition was carried out with $\mathrm{Ti}$ as target in nitrogen reactive environment. Then the substrate was moved to graphite target position and the final fifth layer namely the DLC was deposited. For each layer 30 minutes deposition duration was maintained.

$\mathrm{DLC} / \mathrm{TiN} / \mathrm{Ti} / \mathrm{Cu} / \mathrm{Ni}$ interlayer are supposed to accommodate the mismatch in shear stress induced by the films/substrate and their thermal expansion coefficient. To meet these requirements and to enhance DLC adhesion, each layer should have enough thickness and toughness.

A systematic study was made in order to assess the influence of the process parameters on the final mechanical properties of the coatings. Layers were deposited at a low argon partial pressure of $4 \times 10^{-3} \mathrm{mbar}$, in all the cases. Table 1 shows the relevant deposition conditions used during deposition.

\subsection{Characterization Methods of the Deposited Coating}

The surface topography of the coated specimens was examined using a surface profilometer. A commercial surface profilometer (VEECO VSI) was used to measure thickness of the coating by providing a step on the glass substrate surface. Qualitative coating adhesion test was performed as per VDI standards 3198-1991 [22] using a Rockwell indentation hardness testing equipment (Zwick \& Co. KG) and then the specimens were examined using an optical microscope and SEM.

Micro hardness of the coating was evaluated using a Future Tech - FM 700 equipment, at a load of 50 grams, for a dwell time period of 15 seconds.

Table 1 Deposition conditions used in experiments for multilayer coating (Ni - first layer, $\mathrm{Cu}$ - second layer, TiThird layer, TiN- fourth layer and the DLC - fifth layer) each layer 30 minutes deposition duration on WC substrates.

Thin films were then examined using a Buker AXS (D8 discover) diffractometer. It is incorporated with third generation Gobel mirrors providing the highest X-ray flux density, which is essential for thin films. The CuKa line of a conventional $\mathrm{X}$ - ray source, powered at $35 \mathrm{kV}$ and $25 \mathrm{~mA}$ was used for the experiment. The phase attribution was performed JC-PDF database software.

Coefficient of friction of the coated film was estimated using a standard pin on disc machine (Ducom, TR - 201). The coated substrate was subjected to dry sliding wear test at a constant load of $50 \mathrm{~N}$ and at a sliding speed of 
$150 \mathrm{rpm}$. The test duration was fixed as $900 \mathrm{sec}$. The disc material used was AISI $316 \mathrm{~L}$ stainless steel, hardened to 55 HRc.

The characterization of DLC film was done using a WITec-CRM200 confocal Raman instrument and TEM.

\section{Results and Discussions}

\subsection{Film Orientation-Diffractometer}

The deposited films were characterized by glancing angle X-ray diffractometry (GAXRD). The Figure 3 (varying power) and Figure 4 (varying substrate temperature) represent the GAXRD spectra obtained from the surface of the coated substrates. The power at the target was increased up to $250 \mathrm{~W}$ and the vacuum chamber pressure was kept at a low value of $4 \times 10^{-3}$ mbar. The growth of atoms on the substrate surface involves:

1) Atoms arriving at a distribution which depends on the self shadowing of the coating atom's arrival directions and on the peak and valley of the substrate surface. 2) Atoms diffuse over the surface until they become trapped in low energy lattice sites and incorporated into the growing coating.

Finally, the deposited atoms may readjust their positions within the coating lattice by recovery and recrystallization. When the sputtering is performed at a higher vacuum chamber pressure, it results in collision among the ejected atoms and argon ions. This causes the sputtered atoms to scatter in the chamber and reach onto the substrate surface with a low energy level in randomized directions, which promotes shadowing. The structure promotes shadowing because the high peak points on the growing surface receive more coating flux than the valleys [23].

The atoms ejected from the target material possess high energy level and the sputtering was performed at a low vacuum chamber pressure. Therefore the loss of atoms energy was negligible due to collision with $\mathrm{Ar}$ ions. Hence the ejected target atoms were transported to the substrate surface at a high energy level. A few of them penetrated into the substrate while others bounced back to the chamber itself leaving behind roughness on the substrate surface, which would affect the preferred orientation and growth of the grains which can result in poor adhesion $[22,34]$.

No strong textures were developed in any of the samples, but rather, a mixture with variable relative amounts of Ni :-( 111), (200), (220); Cu :-( 111), (200), (220); Ti: - (110), (220); TiN: - (200), (220), (222) orientations were formed. The sputtering deposition process was performed at a vacuum chamber pressure of $4 \times 10^{-3}$ mbar, which is a low pressure. When sputtering process was operated at low pressures, there was little collisional scattering between the sputtered atoms and the argon ions. Therefore, the loss of energy was minimal during

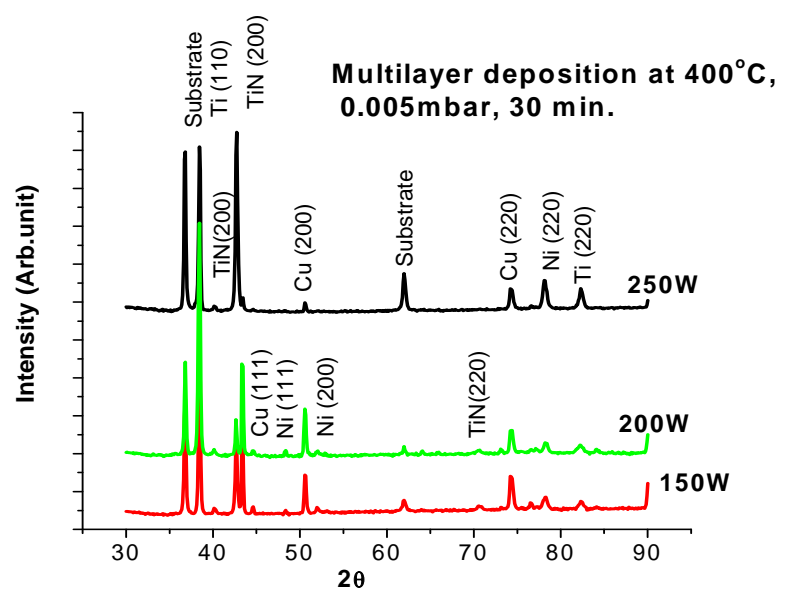

Figure 3. XRD pattern of multilayer deposition of (DLC/ $\mathrm{TiN} / \mathrm{Ti} / \mathrm{Cu} / \mathrm{Ni}$ ) coating coated at $400{ }^{\circ} \mathrm{C}, 0.004 \mathrm{mbar}$, each layer of deposited for a duration of 30 minutes and at $250 \mathrm{~W}$, $200 \mathrm{~W}, 150 \mathrm{~W}$

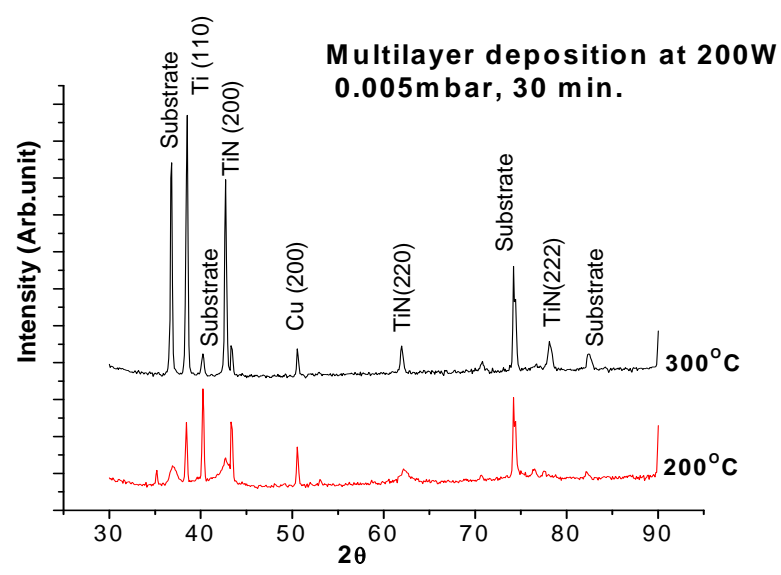

Figure 4. XRD pattern of multilayer deposition of (DLC/ $\mathrm{TiN} / \mathrm{Ti} / \mathrm{Cu} / \mathrm{Ni}$ ) coating coated at $200 \mathrm{~W}, 0.004 \mathrm{mbar}$, each layer of deposited for a duration of 30 minutes and at a substrate temperature of $200{ }^{\circ} \mathrm{C}, 300{ }^{\circ} \mathrm{C}$

transportation from the target to the substrate. This results in an enhanced surface mobility provided by higher ion energy. Also it results in denser packing and enhanced crystal grain growth on the substrate surface.

Nickel formation was observed at $400{ }^{\circ} \mathrm{C}, 200 \mathrm{~W}, 150$ $\mathrm{W}$, but it was not observed at lower substrate temperatures of $300{ }^{\circ} \mathrm{C}$ and $200{ }^{\circ} \mathrm{C}$. $\mathrm{Ni}$ is a magnetic material that needs more surface energy to move along the substrate surface to form crystalline structure and grow layer by layer, which was observed at $400{ }^{\circ} \mathrm{C}$. At a lower surface temperature they do not have enough surface mobility, therefore Ni formation was restricted. Even at $250 \mathrm{~W}$, $400{ }^{\circ} \mathrm{C} \mathrm{Ni}$ was not formed because at higher target power and the decrease in sputtering yield. This is due to the deep penetration of argon ions into the target and the consequent decrease in energy of atoms deposited at the target surface which decrease the sputtering yield. This 
result in a decrease in the number of atoms ejected from the target and consequently low denser packing of the material. Ni (JCPDS - 87 0712) crystalline structure formation was observed at $400{ }^{\circ} \mathrm{C}, 200 \mathrm{~W}$ and $150 \mathrm{~W}$.

At $250 \mathrm{~W}, 400{ }^{\circ} \mathrm{C}$ Copper (200) orientation was observed without maximum intensity peak because at higher target power, the deep penetration of argon ions into the target and the consequent decrease in energy of atoms deposited at the target surface decrease the sputtering yield. This result in a decrease in the number of atoms ejected from the target resulting in a low denser packing of the material. At all deposition conditions $\mathrm{Cu}$ (JCPDS - 85 1326) crystalline structure formation was observed.

Titanium Nitride (TiN) crystalline structure (JCPDS 71 0299) was formed at all deposition condition except at $200{ }^{\circ} \mathrm{C}$. This is because, at a lower substrate surface temperature the energy level of atoms was low and thus the mobility of the atoms along the surface was restricted. Hence crystalline structure formation was not observed.

Ti (JCPDS 65 5970) crystalline structure formation was seen at all deposition conditions with maximum intensity peak.

\subsection{Microhardness}

Figure 5 shows the variation in the micro hardness of multilayer (DLC/TiN/Ti/Cu/Ni) coating coated on a WC substrate with various target powers ranging from $150 \mathrm{~W}$ to $250 \mathrm{~W}$ at a constant temperature of $400^{\circ} \mathrm{C}$, each layer for 30 minutes deposition duration and 0.004 mbar chamber pressure.
At higher target power (250 W) the sputtering yield decreased. Since the ions penetrated deep into the target, the energy deposited at the surface decreased, thereby decreasing the sputtering yield. This results in the formation of non-uniform and less dense microstructure at the substrate surface. This leads to the decrease in micro hardness, formation of defects etc. at a higher operating power of $250 \mathrm{~W}$. The micro hardness is hence less as compared to the target power $200 \mathrm{~W}$ and the maximum micro hardness is observed at $200 \mathrm{~W}$ and the micro hardness values were in the range of $2700-3500$ $\mathrm{kg} / \mathrm{mm}^{2}[22,34]$.

Figure 6 shows the variation in the micro hardness of multilayer (DLC/TiN/Ti/Cu/Ni) coating, coated on a WC substrate at various substrate surface temperatures ranging from $200^{\circ} \mathrm{C}$ to $400^{\circ} \mathrm{C}$ at a constant power of $200 \mathrm{~W}$ and at 0.004 mbar chamber pressure. High surface temperature on the substrate surface enhances the diffusion and surface mobility of atoms, which leads to denser packing of the sputtered atoms on the substrate surface. While depositing DLC, substrate heating was not provided. This is necessary for the formation of $\mathrm{sp}^{3}$-hybridised bonds, which determine the hardness of the DLC coating. All these contributing factors together lead to the improvement in micro hardness of the coated film.

The micro hardness was measured and the composite hardness was observed to be in the range of $2200-3600$ $\mathrm{kg} / \mathrm{mm}^{2}$ as shown in Figure 6. The measurement could not eliminate the effect of the substrate. Hence, the hardness of the DLC films will be definitely more than the composite hardness. This finding is in agreement with other researchers observations.

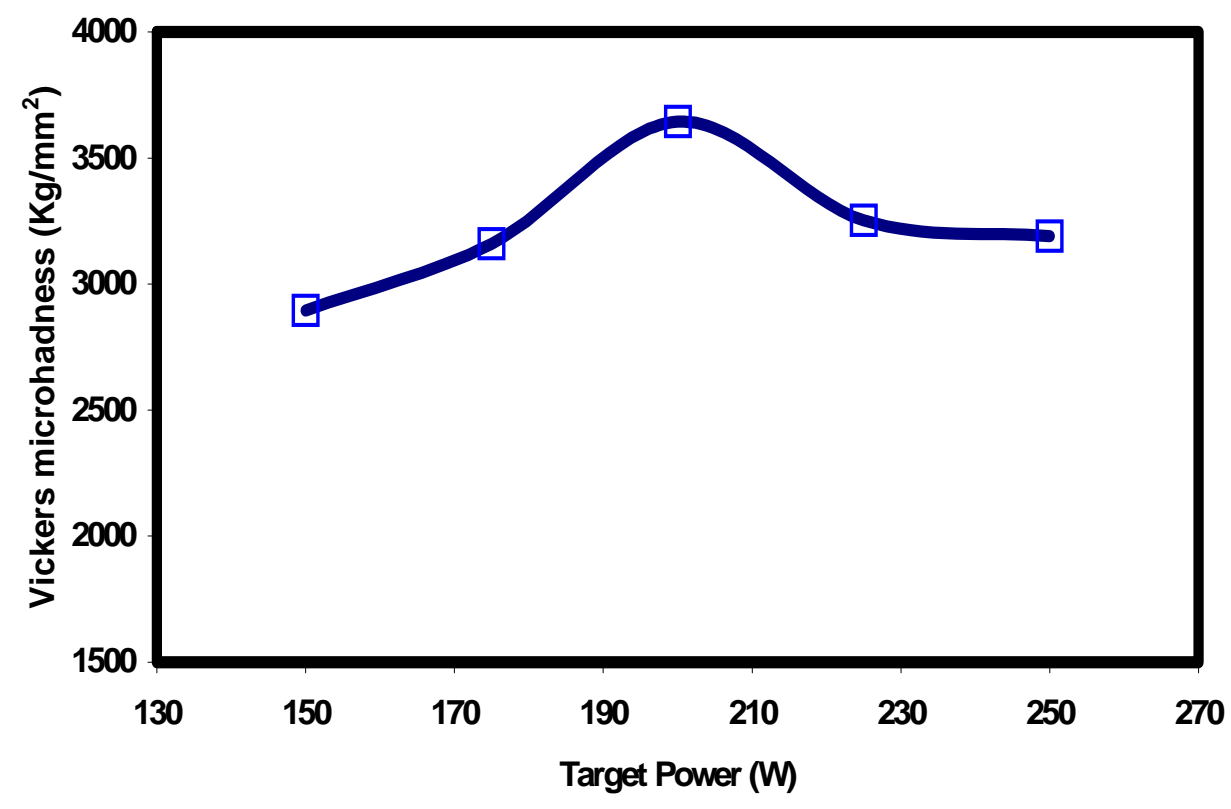

Figure 5. Variation in the Vickers micro hardness of multilayer coating (DLC/TiN/Ti/Cu/Ni) on WC substrate with target power at a constant temperature of $400{ }^{\circ} \mathrm{C}, 0.004$ mbar, and each layer deposited for duration of 30 minutes 


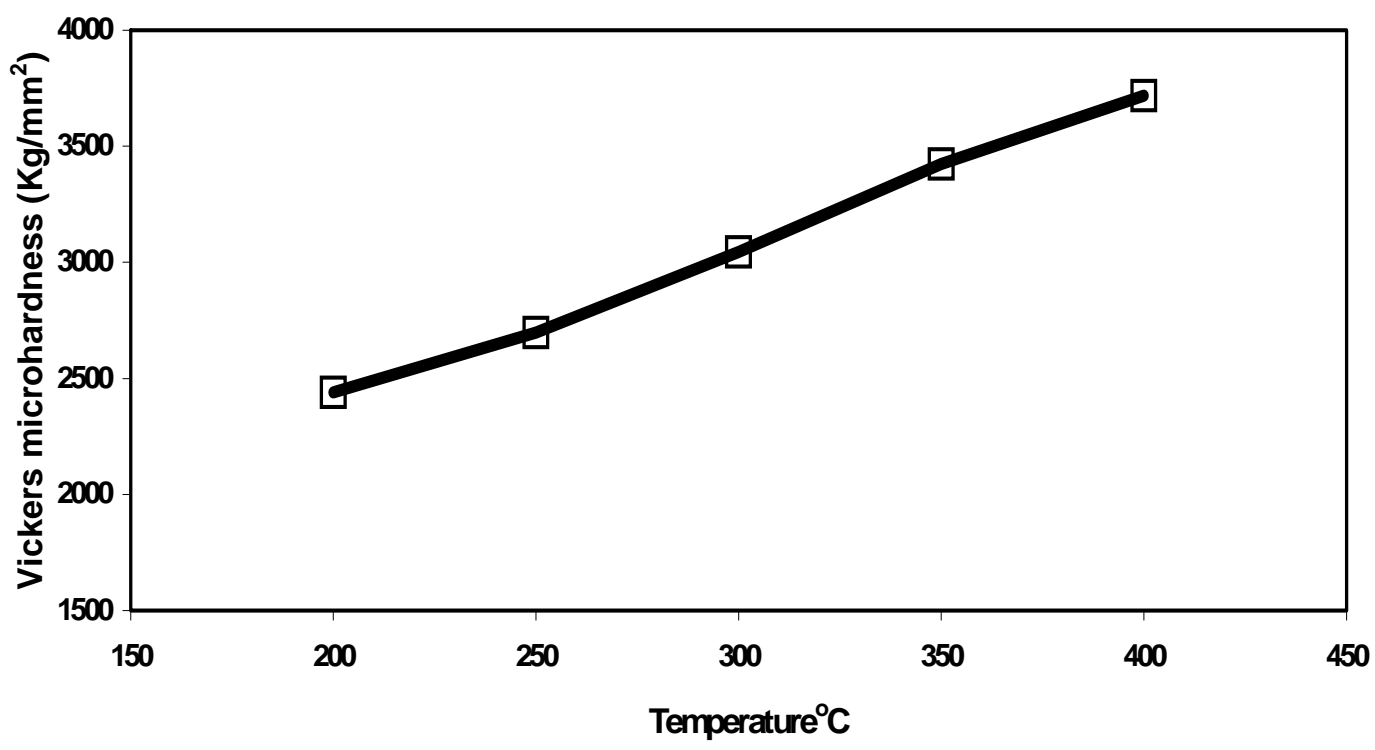

Figure 6. Variation in the Vickers micro hardness of multilayer coating (DLC/TiN/Ti/Cu/Ni) on WC substrate with substrate temperature at constant power $200 \mathrm{~W}, 0.004$ mbar, and each layer deposited for a duration of 30 minutes

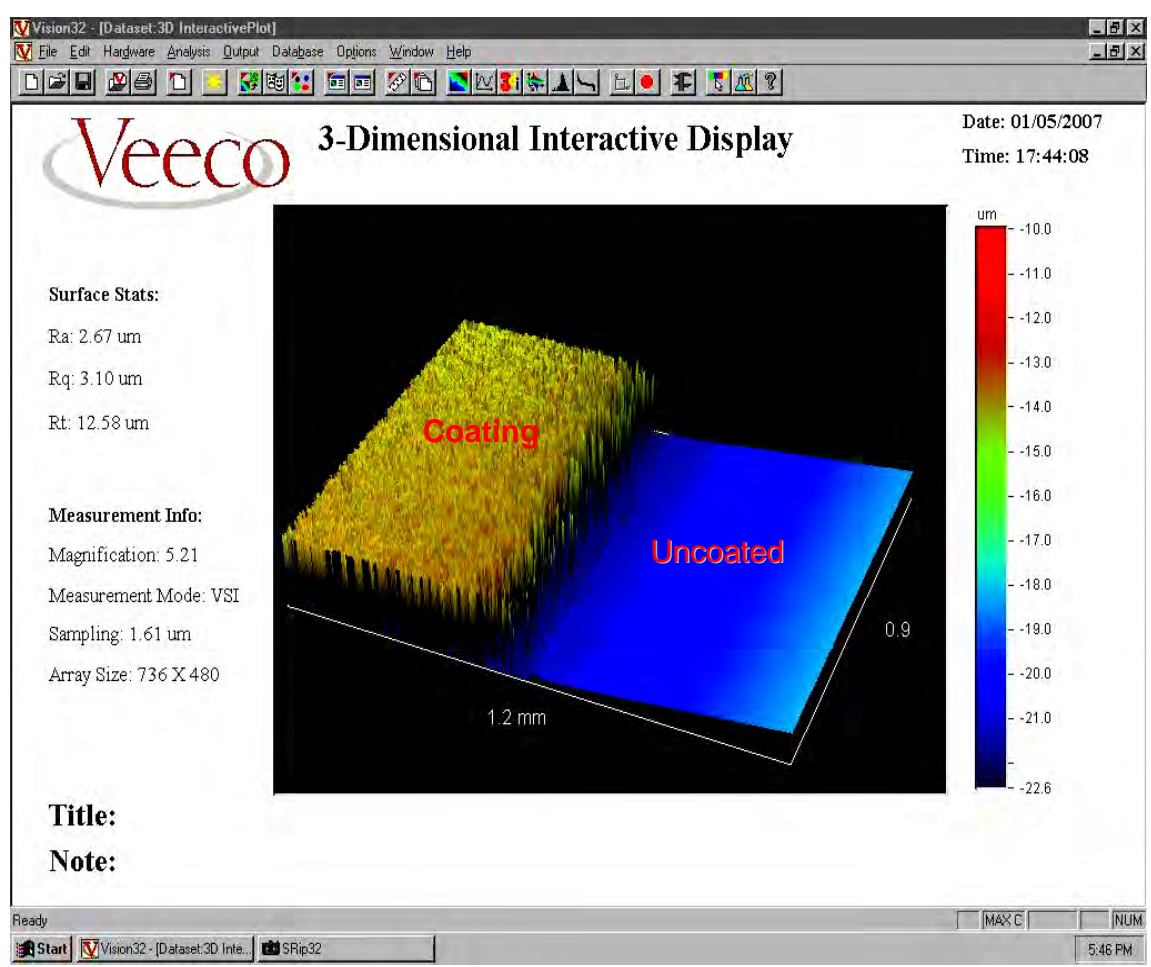

Figure 7. Optical Profilometer (3-D) result showing the rough surface of a typical multilayer (DLC/TiN/Ti/Cu/Ni) coated material on a glass substrate coated at $200{ }^{\circ} \mathrm{C}, 200 \mathrm{~W}, 0.004$ mbar, each layer deposited for a duration of 30 minutes

\subsection{Surface Optical Profilometer}

An optical profiler is used to measure the thickness of the coated film by measuring a step from the top of the film to the bare substrate. The optical profiler is a non contact type instrument, provides three dimensional surface profile measurements.
A typical optical profiler result is shown in Figure 7 at $200{ }^{\circ} \mathrm{C}$ the multilayer coating on a glass substrate becomes rough because mobility of atoms along the substrate surface becomes limited at low temperature. Thus the atoms grow in an isolated fashion such as islands resulting in a rough substrate surface.

A typical 2-D optical profiler output is presented in 
Figure 8, which shows the total thickness of coating (2.6 $\mu \mathrm{m})$ of a typical multilayer (DLC/TiN/Ti/Cu/Ni) coated on a glass substrate. Each layer deposition was performed at constant duration of 30 minutes.

\subsection{Indentation Test Evaluation}

The well known Rockwell ' $C$ ' indentation test is prescribed by the VDI standards 3198, as a destructive qualitative test for coated materials. The principle of this method is presented in Figure 9. A conical diamond indenter penetrates into the coated surface inducing massive plastic deformation to the substrate thereby fractures the coating. The coated specimen was then evaluated using conventional optical microscopy.

The contact geometry, in combination with the intense load transfer, induces extreme shear stresses at the interface. Well adherent coatings will withstand these shear stresses and prevent extended delamination circumferentially. The four different textures (HF1, HF 2, HF3, and HF4) illustrate the indentation shapes (Figure 9) that guarantee strong interfacial bonds between the coating and the substrate. But the delamination (HF5, HF6) at the vicinity of the indentation depicts a poor interfacial adhesion (HF is the German short form of adhesion strength) [19].

It is well known that each layer of graded coating has its own specific function, basically coating acts as a diffusion barrier. The $\mathrm{Ni}$ increases the $\mathrm{Cu}$ adhesion on the substrate. $\mathrm{Cu}$ accommodates the shear stress induced by the films /substrate and mismatch in thermal expansion coefficient, while Ti and TiN promote DLC bonding.

The surface onto which the atoms deposited must have the correct surface energy to promote chemical and physical bonding. In addition, the atoms must arrive with sufficient energy to provide free mobility on the surface. The surface cannot have contaminants that tie up potential bonds that are intended for the atoms depositing on it. This was observed in this investigation at $200 \mathrm{~W}, 400{ }^{\circ} \mathrm{C}$ and 0.004 mbar.

Figures 10, 11, 12, 13, 14 show the acceptable level of adhesion strength of multilayer (DLC/TiN/Ti/Cu/Ni) coating. The power was increased from $150 \mathrm{~W}$ to $250 \mathrm{~W}$ at a constant substrate surface temperature of $400{ }^{\circ} \mathrm{C}$ and then the substrate temperature was varied from $200{ }^{\circ} \mathrm{C}$ to $400{ }^{\circ} \mathrm{C}$ at a constant power of $200 \mathrm{~W}$. Firstly, the strong interfacial adhesion due to intense surface diffusion was promoted by the substrate heating and high impact energy of the bombarding species. These contributing factors together led to higher effective substrate surface temperature, which promotes diffusion. Secondly, it is a well-known fact that impingement islands were nucleated before a continuous film forms. The impingement island size is the size of islands when they begin to impinge on each other. The smaller the impingement island size, the higher the number of grains per unit area which results into smaller grain size, thereby enhances the mechanical strength. Apart from this, due to high power at the target temperature goes up. The impurity from the target surface degasses and desorbs at a rapid rate which enhances coating purity. This resulted in a cleaner substrate surface and a better adherent coating was observed.

The sputtering deposition processes were performed at a low-pressure level of 0.004 mbar. At lower sputtering pressures, the sputtered atoms experience fewer collisions

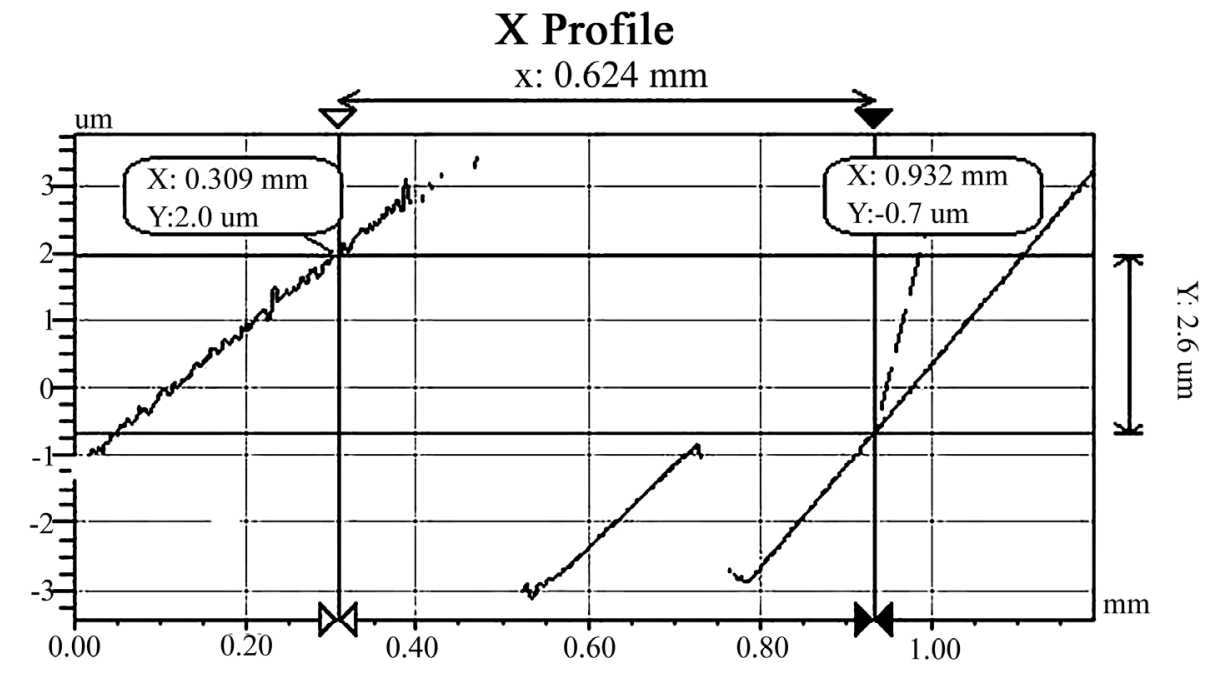

\section{Y Profile}

Figure 8. Optical profilometer (2-D) out put measures the total thickness $(2.6 \mu \mathrm{m})$ of typical multi layer (DLC/TiN/Ti/Cu/Ni) coated on a glass substrate at $400{ }^{\circ} \mathrm{C}, 200 \mathrm{~W}, 0.004$ mbar, each layer deposited for a duration of 30 minutes 
HF1

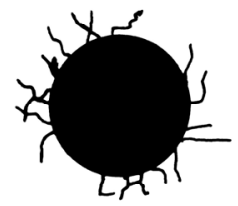

HF 2

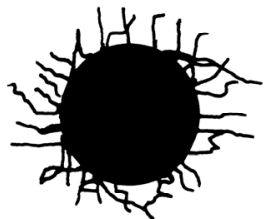

HF3

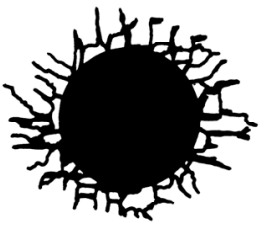

Acceptable level of interfacial adhesion (HF1, HF2, HF3, HF4)

HF 4

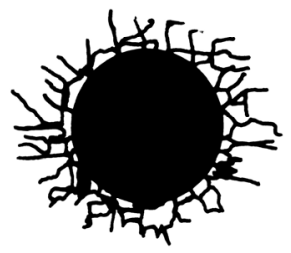

HF5

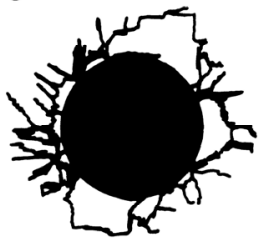

HF 6

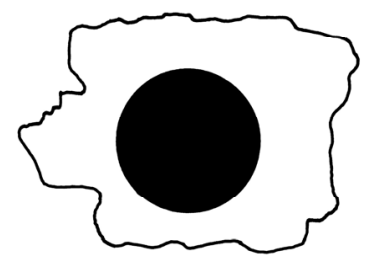

poor interfacial adhesion (HF5, HF6)

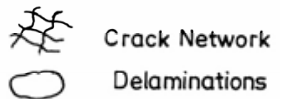

Figure 9. Classification of the acceptable level of interfacial adhesion of thin films based on typical indentation results, according to VDI standard [19]

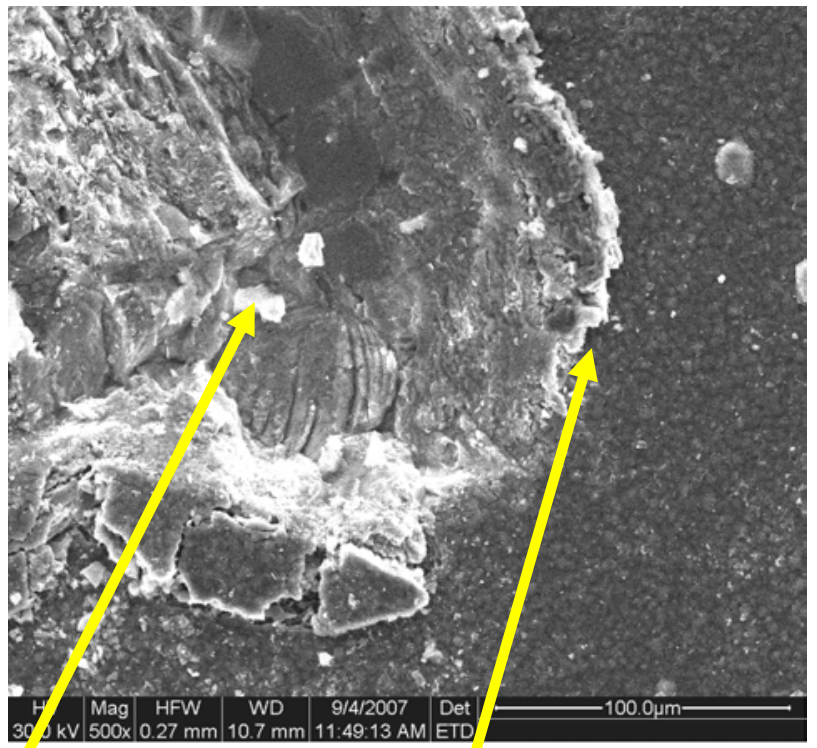

Indentation

no cracks / delamination of coating

Figure 10. Indentation results indicating better adhesion of multilayer (DLC/TiN/Ti/Cu/Ni) coatings coated with $250 \mathrm{~W}$ at a constant substrate (WC) temperature of $400 \mathrm{0C}, 0.004$ mbar, each layer deposited for duration of 30 minutes

scattering with the Ar ions during travel and thus hit on the film surface with more energy leading to a smoothening effect. Besides this, a less disperse ion flux is normally associated to a decrease in self-shadowing effects

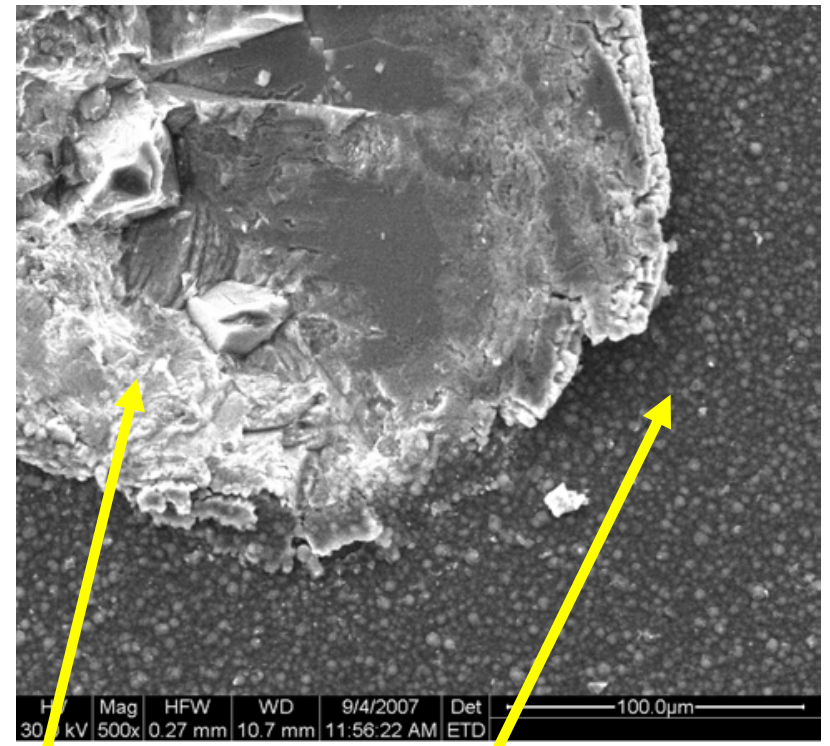

Indentation

no cracks / delamination of coating

Figure 11. Indentation results indicating better adhesion of multilayer (DLC/TiN/Ti/Cu/Ni) coatings coated with $200 \mathrm{~W}$ at a constant substrate (WC) temperature of $400{ }^{\circ} \mathrm{C}, 0.004$ mbar, each layer deposited for duration of $\mathbf{3 0}$ minutes

which also leads to less surface roughening [20,23]. This low chamber pressure deposition process restricts the diffusion of argon ions and other contaminating elements into the film. All these contributing factors together resulted in a stronger adhesion. 
Apart from this, an important requirement is that while depositing DLC coating there should not be any heating of the substrate surface. Since DLC is amorphous and no grain boundaries exist, DLC grows as a hetrolayer above each phase (i.e. nucleate a new phase and grow further). The phase should have the right interfacial energy so

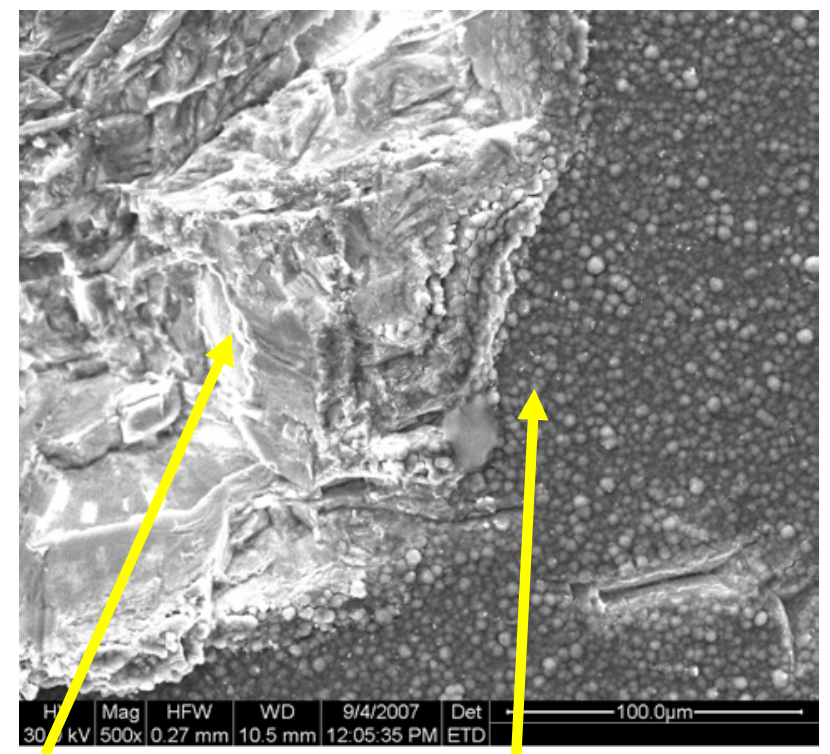

Indentation

no cracks / delamination of coating

Figure 12. Indentation results indicating better adhesion of multilayer (DLC/TiN/Ti/Cu/Ni) coatings coated with $150 \mathrm{~W}$ at a constant substrate (WC) temperature of $400{ }^{\circ} \mathrm{C}, 0.004$ mbar, each layer deposited for duration of 30 minutes

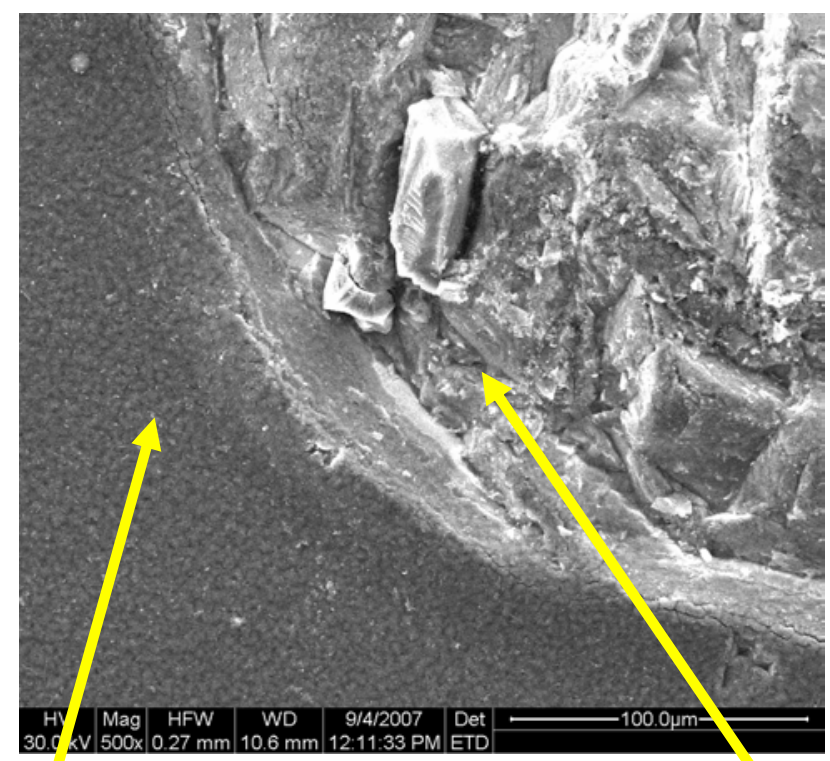

no cracks/delamination of coating

Indentation

Figure 13. Indentation results indicating strong adhesion of multilayer (DLC/TiN/Ti/Cu/Ni) coating coated on WC substrate at $300{ }^{0} \mathrm{C}$ and target power of $200 \mathrm{~W}, 0.004 \mathrm{mbar}$, each layer deposited for duration of 30 minutes

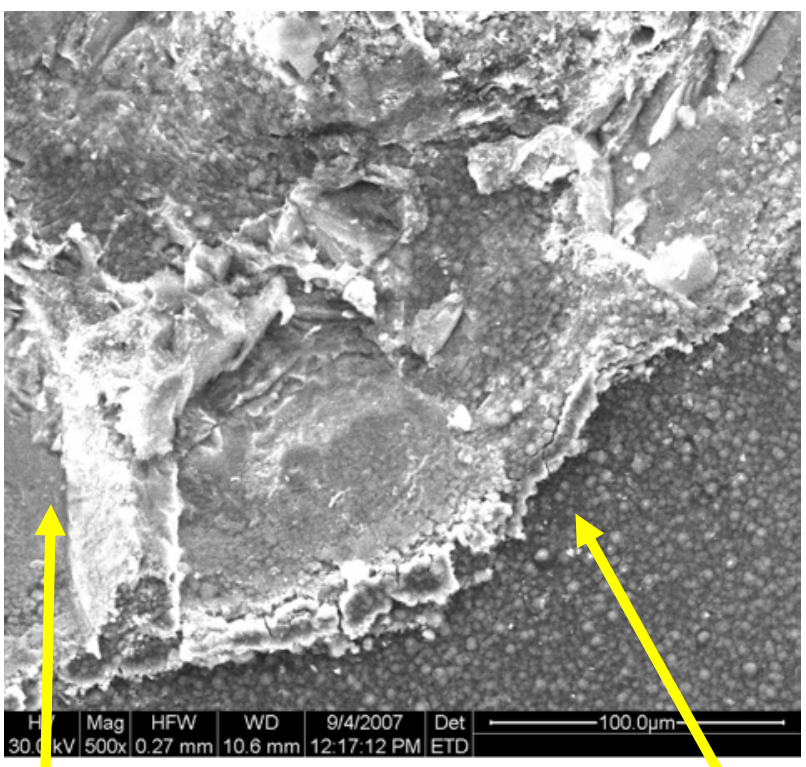

Indentation

no cracks/delamination of coating

Figure 14. Indentation results indicating better adhesion of multilayer coating (DLC/TiN/Ti/Cu/Ni) coated on WC substrate at $200{ }^{0} \mathrm{C}$ and target power of $200 \mathrm{~W}, 0.004$ mbar, each layer deposited for duration of $\mathbf{3 0}$ minutes

that, it cannot form islands. Hence, carbon phase nucleate everywhere on the substrate surface, which prevents the formation of islands since nucleation barrier and carbon atoms do not have enough mobility during deposition process. Therefore, a smooth, amorphous, denser and better adherent coating was formed [35-41].

Figure 15(a), (b), (c) presents the variation in the localized surface defects at various substrate temperatures ranging from $200{ }^{\circ} \mathrm{C}$ to $400{ }^{\circ} \mathrm{C}$ and at a constant power of $200 \mathrm{~W}$. Substrate temperatures higher than $200{ }^{\circ} \mathrm{C}$ are required to achieve strong adhesion and denser grain growth. Higher the substrate temperature more the diffusion and that helps stronger chemical bonding. However, at $450{ }^{\circ} \mathrm{C}$ an embrittiling eta phase formation was reported at the coating substrate interface, which is notorious [42]. Low energy deposition promotes crystallite island formation in the early stages of nucleation due to low surface mobility of atoms. With sufficient surface energy, mobility is high enough to promote coalescence to a continuous film of small thickness, thus increasing the packing density. If the kinetic energy delivered to the surface is below a certain threshold and the ion current density is low, mobility across the surface is limited and empty zones are developed around the larger crystallites as local atoms were captured. This would result in pore and localized defects formation on the films. This is illustrated in the microphotographs shown in Figure 16 (b), (c). The rough surface formed at $200{ }^{\circ} \mathrm{C}$ is clearly seen in the surface profilometer results as well (Figure 8) [43].

SEM micrographs (Figure 16 (a), (b)) show the localized surface pore on the substrate surface at a temperature of 


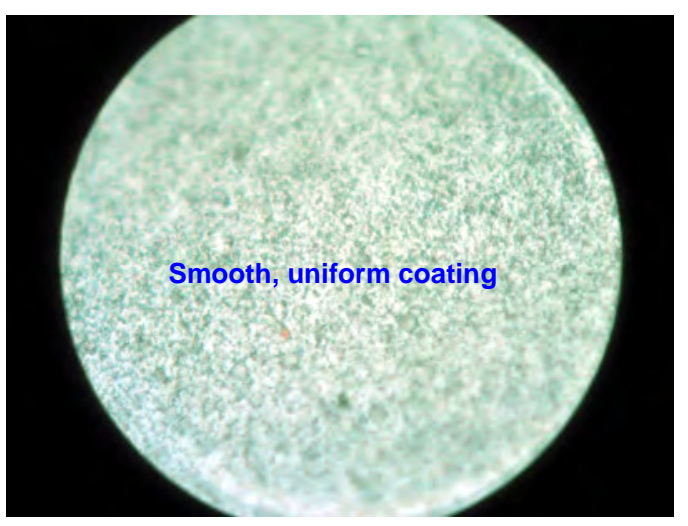

(a) $\mathrm{X} 1000$

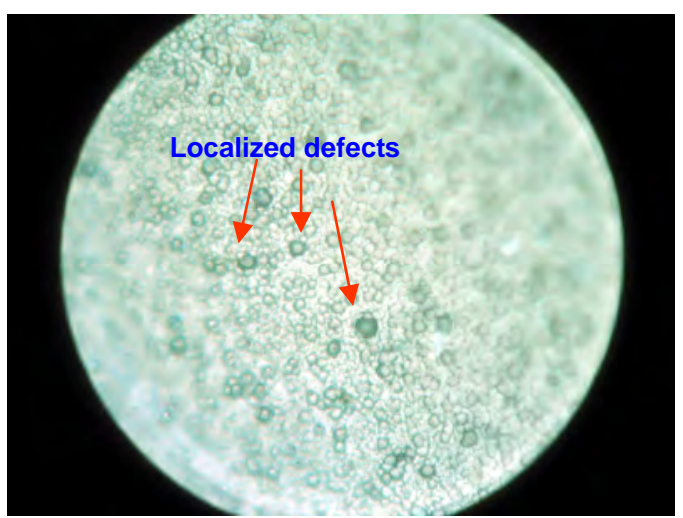

(b) X1000

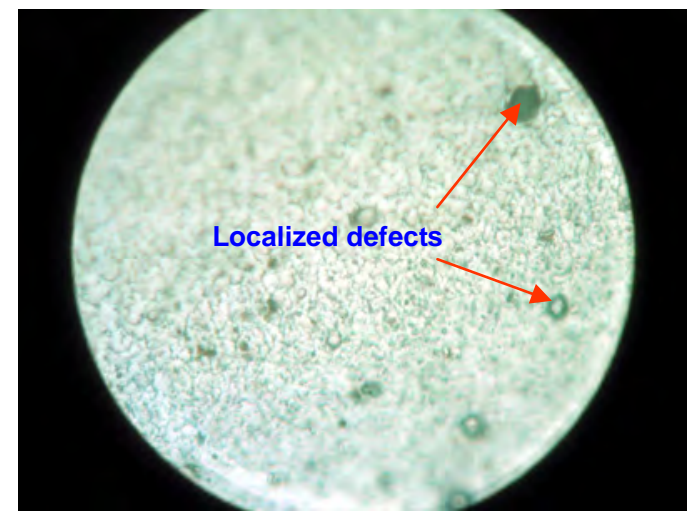

(c) X1000

Figure 15. Variation in the localized surface defects occurred in multilayer coating DLC/TiN/Ti/Cu/Ni, each layer deposited for a duration of 30 minutes at constant power of $200 \mathrm{~W}, 0.004$ mbar with various substrate (WC) temperatures of (a) $400{ }^{\circ} \mathrm{C}$ (b) $300{ }^{\circ} \mathrm{C}$ (c) $200{ }^{\circ} \mathrm{C}$

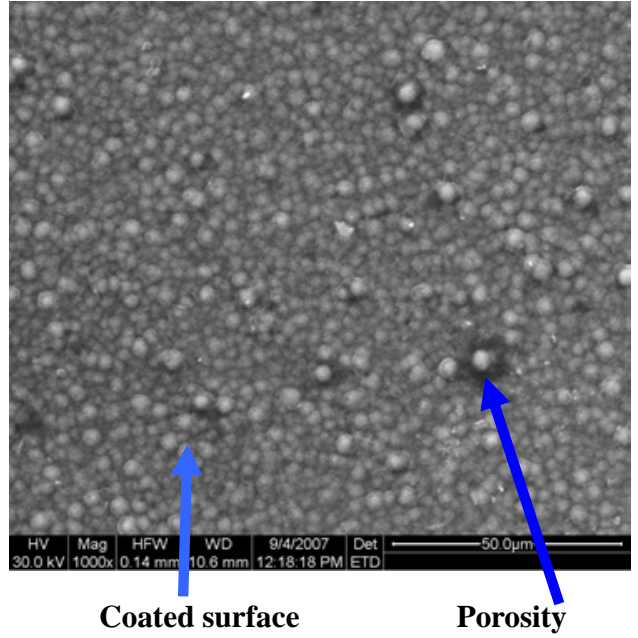

(a)

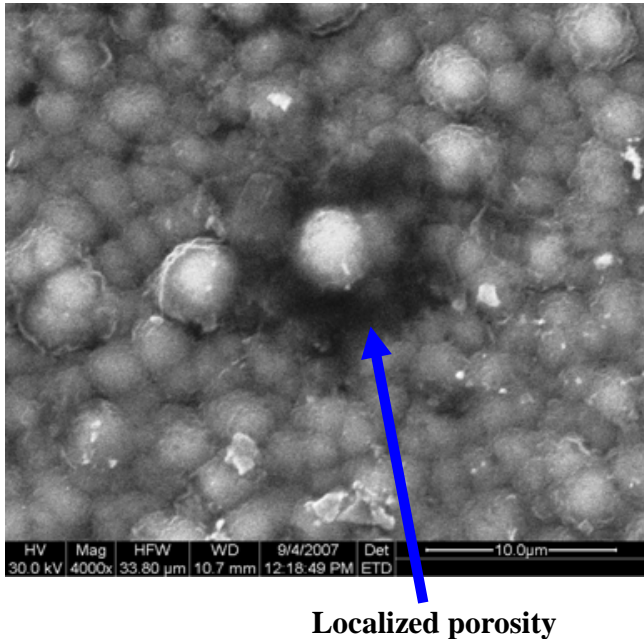

(b)

Figure 16. a, b Localized pore observed on substrate (WC) surface temperature of $200{ }^{\circ} \mathrm{C}$, at a constant power of $200 \mathrm{~W}, 0.004$ mbar, (DLC/TiN/Ti/Cu/Ni multilayer coating, each layer deposited for a duration of 30 minutes) 
$200{ }^{\circ} \mathrm{C}$ and at $200 \mathrm{~W}$. Substrate temperature higher than $200{ }^{\circ} \mathrm{C}$ are necessary to achieve better adhesion and denser grain growth. At substrate temperature $200{ }^{\circ} \mathrm{C}$ and $200 \mathrm{~W}$, the atoms ${ }^{`}$ arrive on the substrate surface with low mobility across the surface and hence densification was inhibited ending up with localized pores. Localized defects and pore are in general beneficial for annihilating the crack propagation.

\subsection{Transmission Electron Microscopy (TEM) Evaluation}

The transmission electron microscope uses high-energy electron beam transmitted through a very thin sample to image and analyze the microstructure of materials with atomic scale resolution. Philips CM12 transmission electron microscope was used for the experiments. Specimens were used approximately1500 $\AA$ or less in thickness in the area of interest. The thin film specimen were prepared and put into copper grid arrangement for measurements. The electrons were focused with electromagnetic lenses and the image was observed on a fluorescent screen, and recorded on a black and white film. TEM is destructive and is generally time consuming.

The representative TEM images of the DLC film are presented in Figure 17(a). which indicates a uniform, pore free, smooth film. The corresponding diffraction pattern is incorporated in Figure 17(b). Microanalysis (EDAX) is

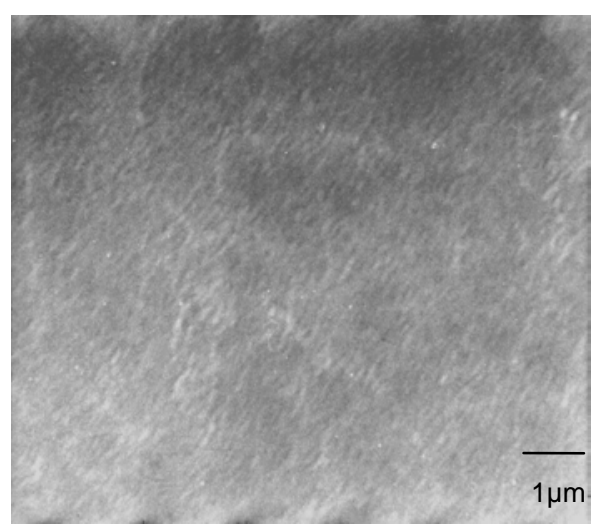

(a)

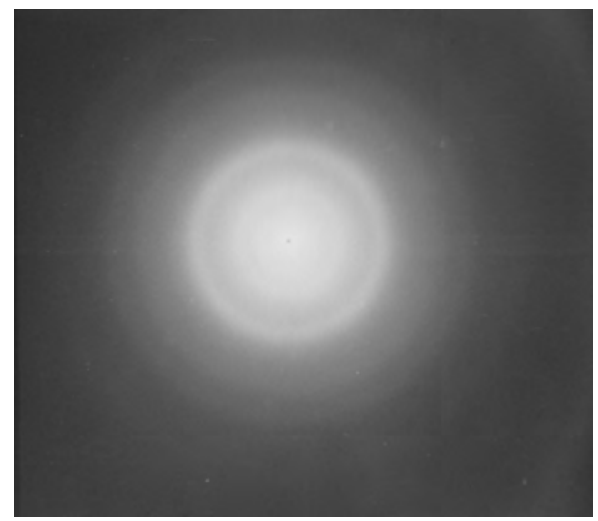

(b)

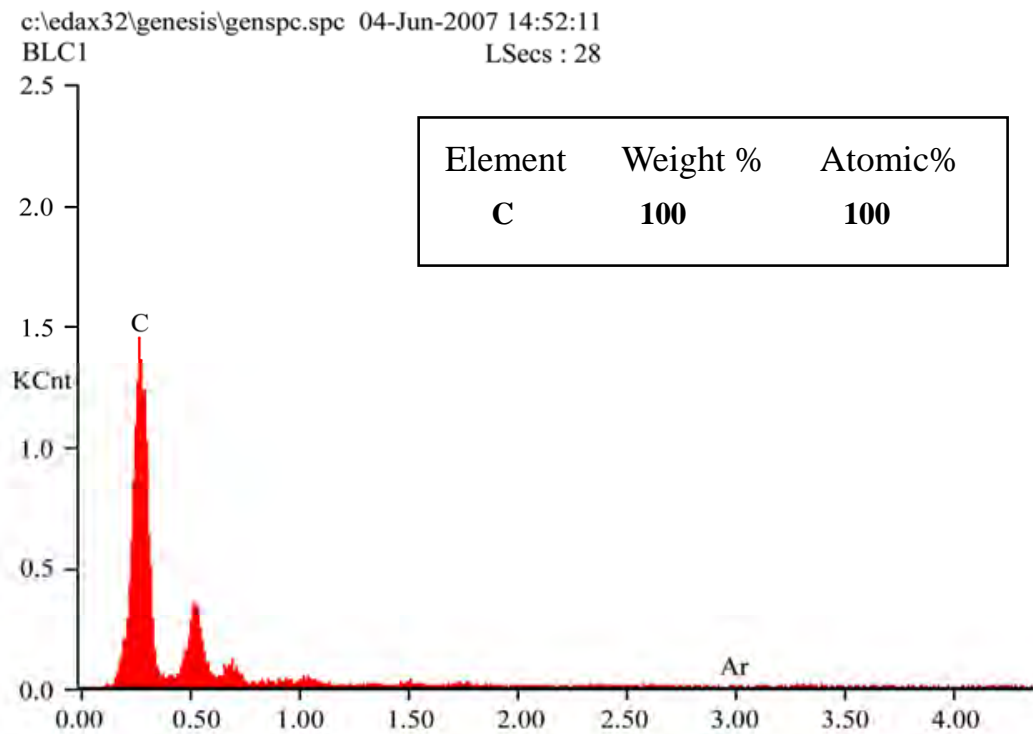

(c)

Figure 17. TEM images of the DLC film (a) uniform, pore free, smooth film (b) No sharp diffraction rings in the diffraction pattern indicates that the material is amorphous (c) EDAX microanalysis indicates $100 \% \mathrm{C}$. DLC deposited on a glass substrate at $0.004 \mathrm{mbar}, 1500 \AA, 100{ }^{\circ} \mathrm{C}, 200 \mathrm{~W}$ 


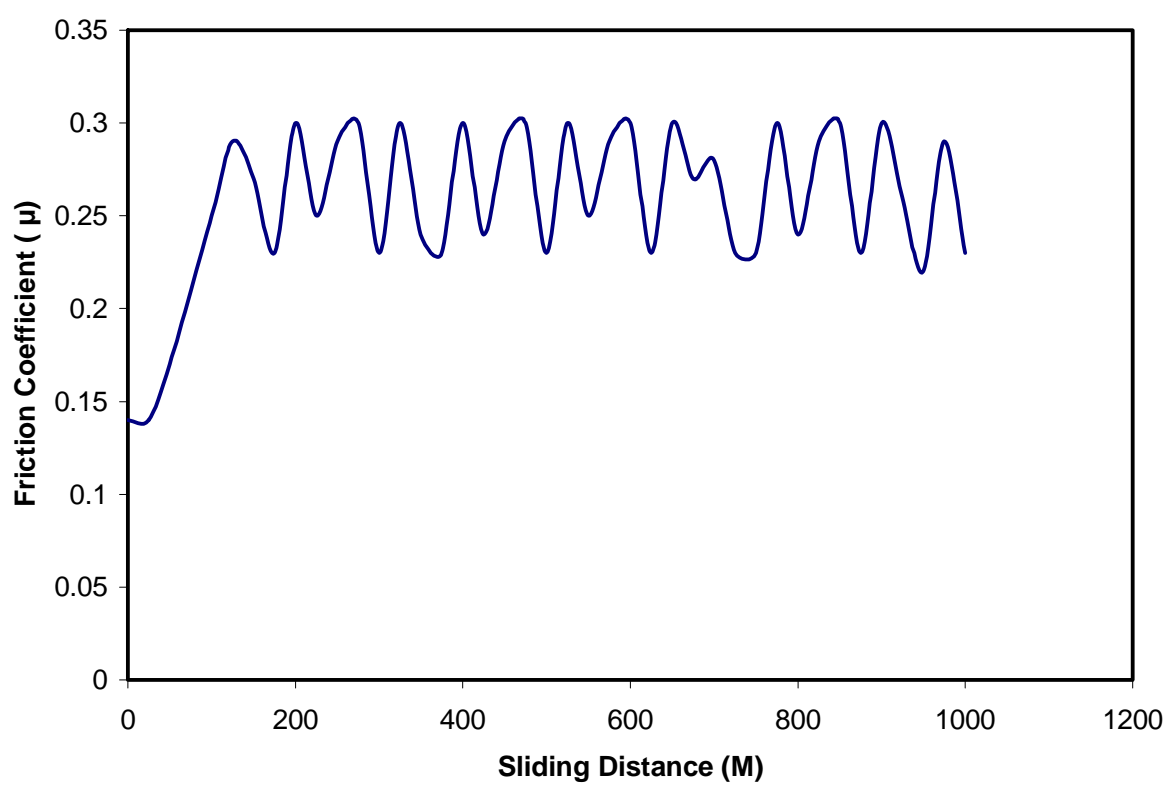

Figure 18. Coefficient of friction of (DLC/TiN/Ti/Cu/Ni) multilayer coated on WC substrate obtained using pin on disc wear test at $200 \mathrm{~W}, 0.004 \mathrm{mbar}, 400{ }^{\circ} \mathrm{C}$, each layer deposited for a duration of 30 minutes

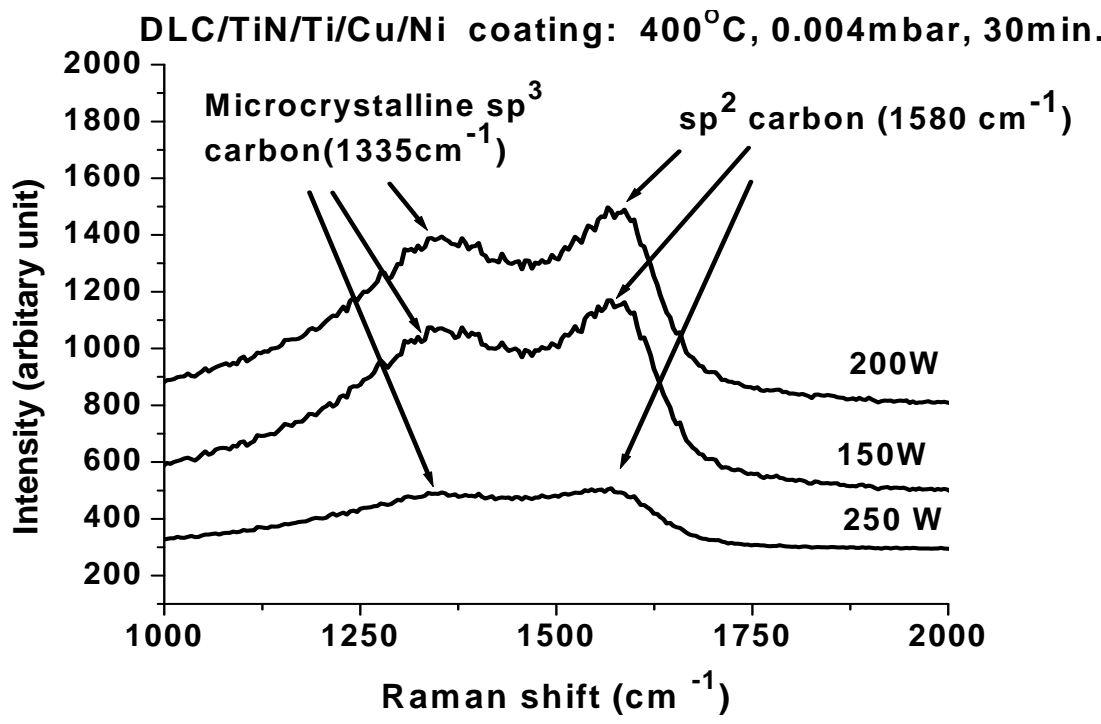

Figure 19. Raman Spectroscopy output showing DLC characterization. multilayer (DLC/TiN/Ti/Cu/Ni) coated on glass substrate at $400{ }^{\circ} \mathrm{C}, \mathbf{0 . 0 0 4}$ mbar, each layer deposited for duration of 30 minutes

presented in Figure 17(c), which indicates the element of carbon present in the film. No sharp diffraction rings in the diffraction pattern suggest that the material is in amorphous form. Thus, it can be concluded that the coating investigated in the present case is an amorphous diamond like carbon [44].

\subsection{Pin on Disc Wear Test}

The variation of coefficient of friction $(\mu)$ of the multilayer (DLC/TiN/Ti/Cu/Ni) coating on WC substrate with sliding distance is shown in Figure 18. DLC coatings were amorphous, continuous, and pore free and had no grain boundaries, which resulted in a very smooth surface. The coefficient of friction values were continuously recorded and the output was obtained during the entire rotation cycle of the disc (Figure 18).

Initially an increase in coefficient of friction was observed. This is due to the anchoring between micro projections present on the substrate surface and disc surface and subsequently this was worn out. But further it was seen that coefficient of friction reached to a steady state 
level. The coefficient of friction is maintained in the range $0.2-0.3$ in all the cases matching with the results of earlier researchers.

\subsection{DLC Characterization by Micro Raman Instrument}

Figure 19 shows Multilayer DLC/TiN/Ti/Cu/Ni coating on glass substrate at $400{ }^{\circ} \mathrm{C}, 0.004 \mathrm{mbar}$, deposited for duration of 30 minutes. The Raman spectrum of DLC films deposited on the glass substrate was smooth and dense. The spectra display the characteristic Raman diamond peak ( $\mathrm{sp}^{3}$ hybridized carbon atoms) positioned at $1,355 \mathrm{~cm}^{-1}$. In addition, a broad band indicates the presence of amorphous carbon phases $\left(\mathrm{sp}^{2}\right.$ hybrid carbon atoms) observed at around 1,580 $\mathrm{cm}^{-1}$.

It is observed that, at $250 \mathrm{~W}, \mathrm{sp}^{3}$ hybrised carbon bond formation is not significant. The Figure 5 shows the micro hardness variation with target power, which clearly indicates that the micro hardness decreased at $250 \mathrm{~W}$. This is due to the penetration of argon ions into the target and the consequent decrease in energy of atoms deposited at the target surface. All these put together decrease the sputtering yield and a decrease in the number of atoms ejected from the target surface resulting in low surface mobility and low denser deposition on substrate surface. Therefore, $\mathrm{sp}^{3}$ formation is restricted which governs the increase in micro hardness. At $150 \mathrm{~W}, 250 \mathrm{~W}$, $\mathrm{sp}^{3}$ formation is significant, therefore maximum micro hardness is observed, which is clearly seen in Figure 5

\section{Conclusions}

Based on a comprehensive experimental investigation carried out on coating of DLC/TiN/Ti/Cu/Ni multilayer using d.c magnetron sputtering, the following observations are presented.

Surface preparation and cleanliness are very important requirement for achieving better adhesion. The micro hardness of coating is the major mechanical property that influences the life and high performance of a surface engineered cutting tool.

The DLC films deposited are fully amorphous, smooth, and pore free and did not show crystalline structure as evidenced by TEM images.

Uniform, continuous, crack free and pore free and strongly adhered multilayer coating could be successfully deposited on WC tool substrate using d.c magnetron sputtering.

The sputter deposition conditions for DLC/TiN/ $\mathrm{Ti} / \mathrm{Cu} / \mathrm{Ni}$ multilayer coatings are identified to achieve improved quality with particular reference to adhesion and surface finish.

Due to the limitation of the sputtering deposition equipment the coating of the cutting tools and their subsequent machining performance studies could not be carried out in this work. Therefore, with sophisticated coating equipment, there is a wide scope for further work to carry out different combinations of layers of coating and machining studies.

\section{REFERENCES}

[1] T. Arai, H. Fujita, and M. Watanabe, "Evaluation of adhesion strength of thin hard coatings," Thin Solid Films, Vol. 154, pp. 387-401, 1987.

[2] P. J. Burnett and D. S. Rickerby, “The relationship between hardness and scratch adhesion,” Thin Solid Films, Vol. 154, pp. 403-416, 1987.

[3] H. Weiss, "Adhesion of advanced overlay coatings: Mechanisms and quantitative assessment," Elsevier Surface and Coatings Technology, Vol. 71, pp. 201-207, 1995.

[4] V. Kiryukhantsev-Korneev, J. F. Pierson, M. I. Petrzhik, M. Alnot, E. A. Levashov, and D. V. Shtansky, "Effect of nitrogen partial pressure on the structure, physical and mechanical properties of $\mathrm{CrB}_{2}$ and $\mathrm{Cr}-\mathrm{B}-\mathrm{N}$ films," Thin Solid Films, Vol. 517, No. 8, pp. 2675-2680, 2009.

[5] E. Bourhis, "Indentation mechanics and its application to thin film characterization,” Vacuum, Vol. 82, No. 12, pp. 1353-1359, 2008.

[6] X. L. Pang, K. W. Gao, F. Luo, Y. Emirov, A. Alexandr Levin, A. Alex, and Volinsky, "Investigation of microstructure and mechanical properties of multi-layer $\mathrm{Cr} / \mathrm{Cr}_{2} \mathrm{O}_{3}$ coatings,” Thin Solid Films, Vol. 517, No. 6, pp. 1922-1927, 2009.

[7] D. V. Shtansky, A. N. Sheveyko, D. I. Sorokin, L. C. Lev, B. N. Mavrin, and P. V. Kiryukhantsev-Korneev, "Structure and properties of multi-component and multilayer TiCrBN/WSe $\mathrm{x}_{\mathrm{x}}$ coatings deposited by sputtering of TiCrB and $\mathrm{WSe}_{2}$ targets," Surface and Coatings Technology, Vol. 202, No. 24, pp. 5953-596, 2008.

[8] J. H. Yang, K. H. Chen, S. Q. Wang, D. H. Xiao, and C. J. Zhu, "Characteristics and performance of Ti(C, N) coatings synthesized by magnetron sputtering technique," Journal of Alloys and Compounds, Vol. 471, No. 1, pp. 162-165, 2009.

[9] K. Chu and Y. G. Shen, "Mechanical and tribological properties of nanostructured TiN/TiBN multilayer films," Wear, Vol. 265, No. 3-4, pp. 516-524, 2008.

[10] J. Gerth and U. Wiklund, "The influence of metallic interlayers on the adhesion of PVD TiN coatings on high-speed steel,” Wear, Vol. 264, No. 9-10, pp. 885-892 2008.

[11] K. W. Chen and J. F. Lin, "The study of adhesion and nanomechanical properties of DLC films deposited on tool steel," Thin Solid Films, Vol. 517, No. 17, pp. 4916-4920, 2009.

[12] F. J. G. Silva, A. J. S. Fernandes, F. M. Costa, A. P. M. Baptista, and E. Pereira, "A new interlayer approach for CVD diamond coating of steel substrates,” Diamond and 
Related Materials, Vol. 13, pp. 828 -833, 2004.

[13] R. L. Chii, T. K. Cheng, and M. C. Ruey, "Improvement in adhesion of diamond films on cemented WC substrate with Ti-Si interlayers,” Diamond and Related Materials, Vol. 7, pp. 1628-1632, 1998.

[14] B. Bhusan Springer Handbook of Nano Technology, New York, pp. 709-711, 2004.

[15] A. G. Naumovets and Y. S.Vedula, "Surface diffusion of adsorbates," Surface Science Reports, North Holland Publishing Company, 4, 365-434, 1985.

[16] A. Tsuchiyama, Y. Shima, and H. Hasuyama, "Adhesive strength of DLC films prepared by ionistaion method," Surface Treatment, Vol. 5, pp. 41-49, 2002.

[17] S. Vepfek and S. Reiprich, "A concept for the design of novel superhard coatings,” Thin Solid Films, Vol. 268, pp. 64-71, 1995.

[18] P. H. Mayrhofer, C. Mitterer, L. Hultman, and H. Clemens, "Microstructural design of hard coatings," A Progress in Materials Science, Vol. 51, pp. 1032-1114, 2006.

[19] V. N. Antoniadis and N. Bilalis, “The VDI 3198 indentation test evaluation of a reliable qualitative control for layered compounds," Journal of Materials Processing Technology, Vol. 143-144, pp. 481-485, 2003.

[20] U. Figueroa, O. Salas, and J. Oseguera, "Deposition of AlN on Al substrates by reactive magnetron sputtering," Surface and coatings technology, Vol. 200, No. 5-6, pp. 1768-1776, 2005.

[21] B. Bhusan, Modern Tribology Handbook, Delta CRC Press, USA, Vol. 2, 2005.

[22] B. Bhusan, "Handbook of tribology: materials, coatings, and surface treatments," Mcgraw-Hill Professional, 1991.

[23] K. Wasa, M. Kitabatake, and H. Adachi (2004) “Thin film materials technology: - Sputtering of compound materials," Springer, William Andrew Inc publishing, New York.

[24] S. J. Bull, "Techniques for improving thin film adhesion," Vacuum, Vol. 43, No. 5-7, pp. 517 - 520, 1992.

[25] S. Schiller, U. Heisig, and K. Steinfelder, “A new sputter cleaning system for metallic Substrates," Thin Solid Films, Vol. 33, pp. 331-339, 1976.

[26] D. M. Mattox and A. Rigney, Chapter 2, “Adhesion processes in technological applications materials science and engineering,” Vol. 83, pp. 189-195, 1986.

[27] D. M. Mattox, "Thin film metallization of oxides in Microelectronics,” Thin Solid Films, Vol. 18, pp. 173-186, 1973.

[28] D. M. Mattox, "Surface effects on the growth, adhesion and properties of reactively deposited hard coatings," Surface and Coatings Technology, Vol. 81, No. 8-16, 1996.

[29] Cerac, “The adhesion problem,” Cerac Coating Material News, Vol. 6, January - March, 1996.

[30] H. P. Bonzel, "A surface diffusion mechanism at high temperature,” Surface Science, Vol. 21, No. 45-60, 1970.

[31] P. G. Shewmon, "Diffusion of impurities along surfaces," Surface Science, Vol. 6, pp. 293-296, 1967.

[32] G. E. Rhead, "Diffusion on surfaces,” Surface Science, Vol. 47, pp. 207-221, 1975.

[33] J. A. Enables, "Nucleation and growth of thin films: recent Progress,” Vacuum, Vol. 33l, pp. 701-705, 1983.

[34] S. Vincent and Smentkowski, "Review trends in sputtering,” Progress in Surface Science, Vol. 64, No. 1-58, 2000.

[35] J. Robertson, “Diamond like carbon,” Material Science and Engineering, Vol. 37, pp. 129 - 281, 2002.

[36] D. M. Mattox and J. E. Macdonald, "Interface formation during thin film deposition,” Applied Physics, Vol. 34, No. 8, pp. 2493, 1963.

[37] J. Robertson, “Amorphous carbon current opinion in solid state,” Materials science, Vol. 1, pp. 557-56, 1996.

[38] J. Robertson, "Deposition mechanisms for promoting $\mathrm{sp}^{3}$ bonding in diamond like carbon, Diamond and related materials,” Vol. 2, pp. 984-989, 1993.

[39] J. Robertson, "hard amorphous (diamond like) carbons," Progress in Solid State Chemistry, Vol. 21, pp. 199-333, 1991.

[40] M. W. Thompson, "Physical mechanisms of sputtering, Physics reports (review section of physics letters)," North Holland publishing Company, Vol. 69, No. 4, pp. 335371, 1981.

[41] B. Bhushan and X. D Li, "Nanomechanical characterization of solid surfaces and thin films," International Materials Reviews, Vol. 48, No. 3, pp. 125-164, 2003.

[42] ASM, "Surface engineering of non metallic materials," Vol. 5, ASM Handbook, ASM International, pp. 902-907, 1987.

[43] F. X. Cheng, C. H. Jiang, and J. S. Wu, "Effect of substrate temperatures on texture in thin films by magnetron sputtering," Materials Letters, Vol. 59, pp. 1530-1532, 2005.

[44] P. J. Kelly and R. D. Arnell, "Magnetron sputtering: A review of recent developments and applications," Vacuum, Vol. 6, pp. 59-72, 2000. 